\title{
LA INTEGRACIÓN DE LAS COOPERATIVAS Y SU COMPETITIVIDAD: LA COOPERATIVA DE BENAGUASIL, LA REALIDAD DE UN SUEÑO.
}

\author{
Gloria Domenech Martínez \\ Profesora Universidad Politécnica de Valencia \\ Email: glodomar@urb.upv.es
}

RESUMEN: El sector agroalimentario es estratégico para la sociedad en general El campo valenciano se enfrenta a problemas estructurales derivados del abandono de las tierras por su escasa rentabilidad, la parca movilidad del mercado de la tierra y una insuficiente adaptación al mercado. y la agroindustria ofrece una excelente oportunidad para el desarrollo del mismo Problemas que, a nuestro entender, se pueden solucionar con alternativas reales que impulsen nuevos procesos productivos vinculados a estrategias de comercialización. Desde esta perspectiva, nos acercamos al proyecto piloto de gestión de la producción llevado a cabo en la Cooperativa Rural San Vicent Ferrer de Benaguasil, situada en Valencia, se postula en pro de la innovación en la gestión y modernización de la producción para potenciar la planificación comercial y la gestión en común.

PALABRAS CLAVE: Nuevas fórmulas jurídicas, innovación en gestión, agroalimentación, modernización de la producción, contrato de gestión y planificación de la producción, cesión de derechos de pagos básicos.

ABSTRACT: The agri-food sector is strategic for society in general. The Valencian country side faces structural problems derived from the abandonment of land due to its low profitability, the limited mobility of the land market and an insufficient adaptation to the market. In our opinion, these are problems that can be solved with alternatives that drive new productive processes linked to marketing strategies. From this perspective, the pilot project of production management carried out in the Cooperativa Rural San Vicent Ferrer of Benaguasil, located in Valencia, is posited in favor of innovation in the management and modernization of production, and to enhance commercial planning and management.

KEYWORDS: New legal formulas, innovation in management, agri-food, modernization of production, management contract and production planning, transfer of basic payment rights. 
SUMARIO:I.- INTRODUCCION:EL SECTOR AGROALIMENTARIO ESTRATEGICO Y PARADIGMA DE INOVACION. II.- LAS COOPERATIVAS EN LA COMUNIDAD VALENCIANA. III.- LA RURAL SANT VICENT FERRER DE BENAGUASIL COOPV: INICIATIVA DE GESTION $Y$ PLANIFICACIÓN D E LA PRODUCCION: III.1.- La Rural Sant Vicent Ferrer de Benaguasil COOPV, III.2.- La iniciativa de la Rural Sant Vicent Ferrer de Benaguasil COOPV(Cooperativa):. II.2.a.- El reto y la colaboración; II.2.b.- Los objetivos del proyecto III.- EL CONTRATO DE GESTIÓN Y PLANIFICACIÓN DE LA PRODUCCIÓN AUSPICIADO POR LA RURAL SAN VICENT FERRER COOPV. III.1.- El contrato agrario: su especialidad III.2.- Las distintas clasificaciones del contrato agrario III.3.- Los elementos del contrato de gestión y planificación de la producción:III.3.a.- El consentimiento;III.3.b.- El objeto;III.3.c.- La causa "especial de los contratos agrarios; III.3.d.- La forma; III.3.e.- El término; III.3.f.- El precio; III.3.g - Las ayudas y pagos a la explotación; III.3.h.La formula de resolver las controversias: mediación. IV.- CONCLUSIONES

\section{I.- INTRODUCCION: EL SECTOR AGROALIMENTARIO ESTRATEGICO Y PARADIGMA DE INOVACION}

El sector agroalimentario es estratégico para la sociedad en general. El campo valenciano se enfrenta a problemas estructurales ${ }^{1}$ derivados del abandono de las tierras por su escasa rentabilidad, la parca movilidad del mercado de la tierra y una insuficiente adaptación al mercado. Problemas que, a nuestro entender, se pueden solucionar con alternativas reales que impulsen nuevos procesos productivos ${ }^{2}$ vinculados a estrategias

\footnotetext{
${ }^{1}$ COMPÉS LÓPEZ, R, MARTINEZ ARROLLO, F, CAMARENO, L, Territorios rurales, la evolución de las políticas de desarrollo rural y la aplicación del segundo pilar de la PAC 2014-2020 en España. Redes de innovación y desarrollo local en el medio rural (COMPÉS LÓPEZ R, ALVAREZ GARCIACOQUE,J.M, y AGUILAR-AVILA Coord), MAAMA. MADRDI. 2015. pág.30. Señalan que a pesar de las muchas y significativas mejoras en el medio rural y las condiciones de vida de sus habitantes, y los cambios en las relaciones entre los territorios urbanos y rurales, el declive de la agricultura y la despoblación siguen amenazando la viabilidad de numerosas áreas rurales españolas. aunque la situación es muy heterogénea, sin nuevos modelos de desarrollo va a ser muy difícil generar empleo y mantener la población rural en España.

2 ATANCE MUÑIZ,I. Sostenibilidad económica de la agricultura española La Sostenibilidad de la Agricultura Española. CAJAMAR CAJA RURAL. (REIG MARTINEZ,E y GOMEZ- LIMON J.A Coord). ALMERIA.2013 pág 89 Señala que "el concepto de sostenibilidad fue universalmente conocido y aceptado a partir de 1987 tras la publicación del Informe Brundtland. La definición más popularizada del mismo es quizá la que reconoce el desarrollo sostenible como aquel que permite satisfacer las necesidades de la sociedad actual sin comprometer la satisfacción de las generaciones futuras"... continua posteriormente "aceptando la imposibilidad de desgajar el concepto de sostenibilidad en sus tres dimensiones (económico, social y ambiental) y evaluar por tanto hasta qué punto un proceso es sostenible o no sólo desde el punto de vista económico.... si pude intentar trasladarse al análisis económico del comportamiento de un sector la dimensión intertemporal o intergeneracional, evaluando hasta qué punto en un futuro un sector, en este caso el agroalimentario, puede mantener o incluso incrementar su capacidad de generación de valor". Posteriormente, en la pág. 112 continua "ha quedado patente la necesidad de alcanzar la triple dimensión de la sostenibilidad para poder asegurar la viabilidad a largo plazo de un agrosistema, condición que trata de resumir en una sola palabra el cada vez más utilizado concepto de resiliencia".

Estos tres pilares son objeto de atención de forma pormenorizada por REIG MARTINEZ,E y GOMEZLIMON J.A. La sostenibilidad de la agricultura actual. La Sostenibilidad de la Agricultura Española. CAJAMAR CAJA RURAL. (REIG MARTINEZ,E y GOMEZ- LIMON J.A Coord). ALMERIA.2013, en la pág. 40 y 41.
} 
de comercialización. Las iniciativas de gestión en común, los bancos de tierras ${ }^{3}$, los huertos sociales y otras experiencias de innovación social son herramientas para posibilitar explotaciones viables y procesos de reestructuración que generen valor añadido y sean respetuosos con el territorio y el medio ambiente.

En este trabajo se lleva a cabo una aproximación al proyecto piloto de gestión de la producción llevado a cabo en la Rural San Vicent Ferrer de Benaguasil COOP.V, situada en Valencia. En este proyecto se aboga por la innovación en la gestión y modernización de la producción para potenciar la planificación comercial y la gestión en común. Siendo objeto de nuestro interés, como luego tendremos ocasión de examinar, los instrumentos jurídico-contractuales que han servido como herramienta a dicha entidad, los contratos de gestión y planificación de la producción.

Entendemos que las características socio-económicas actuales han influido directamente sobre la evolución y transformación de los contratos agrarios y entre ellas cabe destacar el desinterés y la tendencia a la desregulación liberizadora en materia contractual al mismo tiempo que la intervención administrativa, en defensa de la parte más desprotegida, así como en el ámbito de la constante transformación tecnológica de las modernas actividades agrarias y es en este último campo donde debemos ubicar la figura objeto de nuestro análisis. Destacamos el carácter de los contratos agrarios como instrumento para logar conciliar interese contrapuestos no sólo considerando relaciones individuales sino también para la realización de nuevos fines económicos.

En el sector agrario se producen deficiencias estructurales que provocan consecuencias sobre la viabilidad del sector, algunas de las limitaciones más relevantes que impiden la innovación en la gestión y la modernización de la producción podemos agruparlas en torno a tres ejes ${ }^{4}$ :

1.- Aquellas deficiencias ligadas a la falta de motivación al cambio:

1.a.-La elevada edad del titular de la explotación, por lo general mayor de 65 años, y el predominio de la agricultura a tiempo parcial que supone un limitación sobre las capacidades profesionales del sector.

\footnotetext{
${ }^{3}$ DOMENECH MARTINEZ, G. "Los Bancos de Tierra en la Comunidad Valenciana". Fuentes, Política Agraria y Desarrollo Rural, Justicia Agraria y Paz Social. Editorial Jurídica Continental. Costa Rica.2016. pag. 250.

${ }^{4}$ TUDELA MARCO, L Y GARCIA ALVAREZ-COQUE,J.M (Coordinadores). Innovación en la gestión y modernización de la producción en una cooperativa citrícola. Cajamar Caja Rural.España.2016, pag. 21.
} 
1.b.- La escasa expectativa de relevo generacional por la existencia de oportunidades más atractivas fuera de la agricultura.

2.- Aquellas deficiencias ligadas a estructuras económicas débiles y dificultad para adaptarse a la demanda del mercado global

2.a.- La baja productividad y rentabilidad debido a los bajos ingresos de la mayoria de los cultivos y la escasa inversión en las explotaciones.

2.b.- La excesiva fragmentación de las parcelas y la falta de modernización de la mismas.

2.c.- Un calendario productivo no apto a la demanda del mercado

3.- Aquellas deficiencias ligadas a la pérdida gradual de socios e incremento de las tierras cultivables abandonadas

3.a.-Sector atomizado con explotaciones de pequeña escala que supone un reducido margen para negociar los precios.

3.b.- Escaso control sobre la cadena de valor

3.c.- Dependencia de insumos cada vez más costosos

3.d.- Abandono creciente de los cultivos.

Este conjunto de condicionantes conlleva una situación estructural que incide de manera directa sobre la viabilidad del sector agrario, y en particular del cooperativo que es objeto de nuestro análisis. Como posteriormente tendremos ocasión de comprobar, por un lado, influye sobre el propio agricultor que además es socio-cooperativista y se muestran cada vez menos motivación al cambio o a implementar proyectos innovadores o mejoras en sus explotaciones debido a la falta de expectativas de futuro ante cualquier cambio. Por otro lado, en las cooperativas de primer grado, se detecta una pérdida gradual de socios y de producción propia, unida a un incremento de los costes fijos. Las cooperativas se encuentran con dificultades para adaptarse a la demanda del mercado global e inmersas en una espiral de pérdida de confianza en la organización a la par que se va abandonando la tierra. 
En este trabajo vamos a ocuparnos de la iniciativa de la Rural San Vicent Ferrer de Benaguasil Coopv, referida a la iniciativa de gestión y planificación de la producción, para superar de forma simultánea los escollos anteriormente descritos, además de superar aquellos que se pueden generar por las nuevas sinergias.

\section{II.- LAS COOPERATIVAS EN LA COMUNIDAD VALENCIANA.}

La Comunidad Valenciana, al igual que ocurre en otras comunidades autónomas del Estado Español, tiene regulación propia sobre cooperativas. Actualmente dicha competencia se recoge en el art. 49.1.21 a del Estatut d'Autonomía ${ }^{5}$, y en base a dicha atribución la regulación vigente en esta materia se disciplina a través del Decreto Legislativo 2/2015, de 15 mayo, en el que se aprueba el Texto Refundido de Ley de Cooperativas de Comunidad Valenciana.

En la primera redacción del Estatut d'Autonomia ${ }^{6}$ ya se recogía de forma expresa, en el art. $31.21^{\mathrm{a}}$, la competencia exclusiva sobre cooperativas, y a tenor de dicha atribución se dicto la Ley 11/1985 de 25 de octubre de Cooperativas de la Comunitat Valenciana. Con esta primera norma se reconocía la tradición cooperativista de los valencianos quienes, con anterioridad a dicha regulación, en la primera mitad del siglo XIX ya las habían constituido, pero bajo la formulación nacional. Con la regulación autonómica se estableció el modelo y el armazón estructural básico de las que le han seguido. Durante los diez años de su vigencia se experimento se afianzando un modelo cooperativo propio, promoviendo un importante impulso y crecimiento,

Frente al carácter de la norma dirigista y paternalista de la norma encontramos a un cooperativismo maduro y con una solida capacidad de gestión que hizo necesario el cambio legislativo, dando lugar la Ley 3/1995, de 2 de marzo, de la Generalitat, de Cooperativas de la Comunitat Valenciana, vigente hasta la aprobación, en 1998, del Texto Refundido de la Ley de Cooperativas de la Comunitat Valenciana ${ }^{7}$.

El propio Texto Refundido aprobado en 1998 fue, a su vez, objeto de dos reformas, introducidas por las Leyes de Medidas Fiscales, de Gestión Administrativa y Financiera, y de Organización de la Generalitat aprobadas en 1998 y 2001.

\footnotetext{
${ }^{5}$ Reforma operada en el mismo por la Ley Orgánica 1/2006, de 10 de abril 2006

${ }^{6}$ Ley Orgánica 5/1982, de 1 de julio de 1982.

${ }^{7}$ Decreto Legislativo 1/1998, de 23 de junio del Consell
} 
De nuevo, el legislador autonómico mediante Ley 8/2003, de 24 de marzo, de Cooperativas de la Comunitat Valenciana, da entrada a las necesidades e inquietudes del movimiento cooperativo valenciano, en tanto que el texto es el resultado de un amplio consenso entre los poderes públicos valencianos y las propias cooperativas, representadas por la Confederación de Cooperativas de la Comunitat Valenciana. La norma surge de la necesidad de disponer de un texto moderno, claro y flexible, además otorga mayores competencias a los propios estatutos sociales y a las normas de orden interno como medio de favorecer la autorregulación de los diferentes intereses que confluyen en el seno de las cooperativas.

No obstante, dicha norma ha sufrido diversas modificaciones posteriores introducidas por las Leyes de Medidas Fiscales, de Gestión Administrativa y Financiera, y de Organización de la Generalitat aprobadas en 2004, 2007, 2010, 2011 y 2012, principalmente por la adaptación de su texto a los cambios operados en la normativa contable de aplicación general y por la introducción, en 2012, de la posibilidad de construir y mantener cooperativas de trabajo asociado que cuenten únicamente con dos socios.

De nuevo, el consenso permite la publicación de la Ley 4/2014, de 11 de julio, de Cooperativas de la Comunitat Valenciana, que avanza en la armonización con el resto de la legislación cooperativa española en algunas de sus regulaciones esenciales. En el texto se ha actualizado el régimen jurídico de la cooperativa, sus conceptos, clases y estructuras representativas y se les ha dotado de modernas herramientas jurídicas en materia de operaciones societarias y en la participación de sus socios. También, se ha mejorado el sistema de resolución extrajudicial de los conflictos planteados en su seno. Además, con dicha norma se pretende superar los errores de interpretación, con respecto al significado, contenido y alcance de las aportaciones económicas de los socios al capital de la cooperativa, trazando una clara frontera con las aportaciones económicas en las sociedades de capital.

Ante la variedad de normas que regulan la materia en la disposición final primera de la Ley 4/2014, de 11 de julio, de modificación de la Ley 8/2003, de 24 de marzo de Cooperativas de la Comunitat Valenciana, se autoriza al Consell para que mediante decreto legislativo apruebe un texto refundido de la Ley de Cooperativas de la Comunitat Valenciana, al que se incorporarán las disposiciones vigentes sobre la 
materia y las contenidas en la Ley de Cooperativas, aclarándolas y armonizándolas., dando lugar a la actual regulación a través del Decreto Legislativo 2/2015, de 15 mayo, Texto Refundido de Ley de Cooperativas de Comunidad Valenciana, la vigente regulación en esta materia.

Con esta breve referencia a la reglamentación en el ámbito del cooperativisto en la Comunidad Valenciana se puede apreciar el espíritu cooperativista en nuestro territorio y la evolución que el mismo ha operado a la par que la sociedad, mostrando el marco legislativo en el que se encuentra en la actualidad la cooperativa Rural San Vicent Ferrer de Benaguasil Coopv, objeto de nuestro interés.

\section{III.- LA RURAL SANT VICENT FERRER DE BENAGUASIL COOPV: INICIATIVA DE GESTION Y PLANIFICACIÓN D E LA PRODUCCION}

Como ya hemos adelantado en líneas anteriores, el sector agrario valenciano afronta un desafío estructural. El abandono progresivo de los cultivos y la escasa modernización de las explotaciones. En este contexto vamos a tratar la peculiaridad de la iniciativa de gestión y planificación de la producción implementada por la Rural Sant Vicent Ferrer de Benaguasil COOPV (Cooperativa) en el territorio de su influencia.

\section{III.1.- La Rural Sant Vicent Ferrer de Benaguasil COOPV}

La Rural Sant Vicent Ferrer de Benaguasil COOPV (Cooperativa). fue fundada en 1944, se encuentra ubicada en la comarca del Camp del Turia en el municipio de Benaguasil (Valencia). Si bien, en 1997 se integraron las cooperativas de Sant José de Vilamarxant y Rural San Vicent Ferrer de Benaguasil. Principalmente, despliega su influencia en los municipios de Benagasil y Vilamarxant, proyectándose a los términos municipales colindantes. Su actividad inicial se centró, en los primeros años, en la distribución de productos agrícolas y la comercialización de maíz. Posteriormente, en los años sesenta, su actividad principal se centro en la producción, confección y comercialización de cítricos. En la actualidad, más del $80 \%$ de los productos comercializados son cítricos, alrededor de un $10 \%$ es la sandia y el $10 \%$ restante lo componen otras frutas y hortalizas.

La Rural Sant Vicent Ferrer de Benaguasil COOPV (Cooperativa) está integrada por seiscientos socios, si bien sólo cuarenta de ellos viven exclusivamente de la agricultura 
En su seno se han constituido tres secciones: hortofrutícola, suministros y crédito $^{8}$. La plantilla de empleados fijos asciende a doscientos veintisiete, número que se ve incrementado, en épocas de máxima producción puede llegar a los 400 empleados. El territorio de su influencia es de aproximadamente mil hectáreas, 600 de las cuales se dedican a la producción de cítricos, con una superficie media de cada parcela de cuatro hanegadas ${ }^{9}$. A través de sus infraestructuras de almacén y procesamiento tiene una capacidad para procesar cincuenta mil toneladas de cítricos anuales ${ }^{10}$ No obstante, en la actualidad sólo gestiona una media de veinticinco mil toneladas de cítricos, de los cuales son de producción interna dieciocho mil toneladas. Su nivel de facturación medio es de quince millones de euros.

La dirección de la cooperativa, ante la falta de producción agrícola citrícola que permita rentabilizar las instalaciones, coordina las capacidades de producción internas y las demandas de sus socios comerciales, fundamentalmente la cooperativa de segundo grado ANECOP, aportando tareas de gestión y los recursos técnicos necesarios tendentes a la obtención de productos de calidad y sostenibles con el medio ambiente

\section{III.2.- La iniciativa de la Rural Sant Vicent Ferrer de Benaguasil COOPV (Cooperativa).}

\section{II.2.a.- El reto y la colaboración}

La Cooperativa se encontraba, por un lado, con una cooperativa cuyas instalaciones estaban infrautilizadas por la falta de productos agrícolas que permitirán su comercialización a través de la misma, menoscabando el cometido de la cooperativa cuyo objetivo es desplazar hacia el socio el mayor porcentaje posible del incremento del valor del producto agrícola que éste alcanza en el mercado ${ }^{11}$.

Por otro lado, la comarca del Camp del Turia, territorio donde se encuentra la Cooperativa no es una excepción a las deficiencias estructurales que se observan en

\footnotetext{
${ }^{8} \mathrm{~A}$ tenor del contenido del art 8., referido a las secciones de una cooperativa, del Decreto Legislativo 2/2015, de 15 de mayo, del Consell, por el que aprueba el texto refundido de la Ley de Cooperativas de la Comunitat Valenciana. DOGV núm. 7529 de 20.05.2015

${ }^{9}$ Recordemos que la hanegada o fanega es una medida de referencia para designar la superficie agraria cuyo valor varía según regiones. La hanegada valenciana equivale a $831 \mathrm{~m} 2$.

${ }^{10}$ Trabajando con dos turnos en almacén.

11 GOMEZ LOPEZ, J. D. " Las cooperatvas agrarias de la Comunidad Valenciana" Cuadernos de Geografia. núm. 75, 2004, pag.13. La preocupación por alcanzar cooperativas agrarias de mayor tamaño crece en la medida que aparecen como un instrumento idóneo para proteger al pequeño y mediano agricultor de la competencia de otras empresas agroalimentarias, mediante el abaratamiento de los costes de producción, incremento del valor añadido y aumento de los márgenes comerciales.
} 
distintas áreas citrícolas valencianas y a las que nos hemos referido en líneas anteriores.

Este abandono de los cultivos se manifiestan en el paisaje y en el deterioro progresivo de las infraestructuras agrarias: caminos, sistemas de riego, lindes, márgenes de piedra, etc....

Al problema de la falta de producción, desde la perspectiva de la Cooperativa, se añade el abandono de cultivos que en muchas zonas de España se relaciona con un mayor riesgo de incendios, degradación y erosión de los suelos. Problemas que afectan a la gestión del territorio por entender que asociados al abandono son una tendencia inevitable y ajena a nuestro alcance, traspasado el ámbito productivo pero que afecta a toda la cadena de valor y al territorio . El sector agroalimentario, en su conjunto, tiene un papel importante que cumplir desde el punto de vista económico, social, cultural y medioambiental. No podemos obviar que el desarrollo económico asociado a la agricultura, como la industria agroalimentaria y los servicios relacionados suponen una fuente de ingresos relevantes por afectar a campos tan diversos como los industrias de embalajes, transportes, servicios, suministros, seguros, maquinaria, recursos humanos, etc...

Las cooperativas, desde la perspectiva socioeconómica, en el territorio de su influencia ejercen un papel clave en el sector productivo basado en la explotación familiar y con la participación de un porcentaje elevado de dicha población que resulta fundamentar para mantener la viabilidad económica de la zona. Además, desde el punto de vista medioambiental gestiona directamente los recursos naturales y genera paisaje agrario en su área. La situación descrita hace necesaria la implicación de las mismas en aquellas actividades tendentes a impulsar el desarrollo territorial y la creación y mejora en la calidad de empleo ${ }^{12}$.

Situación que llevo a la Cooperativa Rural San Vicent Ferrer de Benaguasil a proponer una alternativa a la elevada tasa de abandono a la vez que se potenciaba su actividad como entidad productora. Se trataba innovar, pero dirigida a la gestión y la modernización de las parcelas. Esta iniciativa fue considerada por la Fundación Cajamar

\footnotetext{
${ }^{12}$ LÁNDERER N. Acciones de aumento del valor añadido de la producción. Estrategias Colectivas para el Desarrollo Rural: El Caso de las Cooperativas de la Comunidad Valenciana. (ORTIZ,D y MESTRE, M Coord.). FECOVA.VALENCIA. 2008 pág.42 Así se señala al entender que la búsqueda de alternativas para producciones estacionales es también uno de los factores fundamentales de esta diversificación, lo que lleva implícito una mejora laboral por verse ampliada la necesidad de personal durante otros periodos del año.
} 
que valoró positivamente la propuesta y junto con el Departamento de Economía y Ciencias Sociales (DECS) de la UPV, se diseño una primera fase de un programa de gestión en común y planificación de la producción.

\section{II.2.b.- Los objetivos del proyecto}

Como objetivo principal $^{13}$ se consideró la optimización de la producción de cítricos y potenciar su comercialización a través de las siguientes actuaciones:

1.- Gestión en común de las parcelas.

\section{2.- Reconversión varietal}

3.- Adaptar la oferta a la demanda del cliente

\section{4.- Aumentar y planificar la producción propia}

La Cooperativa pretendía alcanzar una producción propia de veintisiete mil quinientos millones de kilos de cítricos. Para alcanzar esta cuantía es necesario aumentar la producción propia entre seis y siete millones de kilogramos y para ello se prevén el incrementar la superficie cultivada en dos mil hanegadas.

A medio plazo en el proyecto se incorporaran a la Cooperativa nuevas superficies de tierras e incrementara el rendimiento global contribuyendo a evitar su abandono. A largo plazo se fomentará una mayor profesionalización de la gestión de las parcelas, asociada a mejores condiciones de rentabilidad, que constituyan una oportunidad laboral para los jóvenes y favorezcan el relevo generacional.

Sólo será objeto de nuestro análisis aquella actuación referida a la gestión en común de parcelas. En este proyecto, se persigue incorporar tierras en producción y mejorar su rentabilidad bajo la dirección de la Cooperativa a través de dos vías de implementación:

1- Reconversión directa: inversión por parte del socio cooperativista con subvenciones del $50 \%$ por el programa operativo y la posibilidad de financiación a través de la entidad Caja Mar. El socio proactivo que introduce mejoras en su parcela con apoyo y cooperación de la cooperativa.

13 TUDELA MARCO, L Y GARCIA ALVAREZ-COQUE,J.M (Coordinadores). Innovación en la gestión y modernización de la producción en una cooperativa citrícola. Cajamar Caja Rural.España.2016, pag. 23 
Será el socio quien realiza la inversión y se compromete a gestionar la producción con el apoyo y asesoramiento por parte del equipo técnico de la Cooperativa. A través de esta vía se activa que los socios adopten un rol activo en la modernización de sus explotaciones.

2.- Reconversión por cesión. Firma de un contrato de gestión y planificación de la producción de la parcela por quince años entre el propietario y la cooperativa. La Cooperativa es la entidad que gestiona directamente la producción de las parcelas . Esta es objeto de nuestro interés.

Esta fórmula de Reconversión por cesión está dirigida tanto a los socios de la cooperativa como a otros propietarios externos. Pero sólo aquellas parcelas que reúnan las siguientes condiciones son susceptibles de ser incorporadas al proyecto cumplan como dimensiones mínimas la media hectárea ${ }^{14}$ y estén situadas en zonas con una climatología adecuada al cultivo planificado.

A través de esta fórmula la Cooperativa asume el control y la gestión de las parcelas previo acuerdo con el socio o propietario externo, añadiendo a su papel de mera comercializadora en pro de aquel más proactivo. Deviene en el centro de decisión en torno a la toma de decisiones sobre la gestión y planificación de las parcelas, asumiendo aquellas decisiones referidas a la variedad a cultivar, el momento de su recolección y los tratamientos durante el cultivo.

Por ambas vías de reconversión se promueve la producción planificada, la gestión de las parcelas por socios cada vez más profesionalizados y se refuerza la gestión de dirección y el liderazgo de la Cooperativa.

\section{III.- EL CONTRATO DE GESTIÓN Y PLANIFICACIÓN DE LA PRODUCCIÓN AUSPICIADO POR LA RURAL SAN VICENT FERRER COOPV}

Los estudios referidos a los contratos y, en concreto a una o otra figura contractual agraria, el arrendamiento, enfiteusis, etc...., han sido frecuentes. Pero son pocos los

\footnotetext{
${ }^{14}$ Dimensión mínima establecida atendida la realidad de la Cooperativa de Benaguacil
} 
autores que estudian el concepto de contrato agrario como categoría jurídica ${ }^{15}$, no hay ni unanimidad, entre ellos, en la clasificación de los mismos.

\section{III.1.- El contrato agrario: su especialidad}

En la doctrina clásica, sobre todo la italiana, se restringía el ámbito de aplicación de "lo agrario" a los negocios jurídicos vinculados con la trasmisión o cesión de tierras cultivable. Por lo que los contratos agrarios "carecían de autonomía conceptual, sin alcanzar entonces tipicidad alguna, fuera de sede civil, o más bien, esta podía explicarlos suficientemente. En España, la regulación de los contratos agrarios también participan de las generalidades del Código Civil, aunque se aprecia en algunos de ellos, tales como los clásicos arrendamientos rústicos, la aparcería, etc, que inician en la década de los años treinta, una evolución hacia la especialización, y a partir de este momento, van rugiendo fórmulas especiales tales como, los seguros agrarios, cooperativas agrarias, sat, etc...

Para los autores de tradición civilista el contrato agrario no es más que un tipo de contrato del Código civil, que es aplicable en el ámbito de lo agrario, haciendo innecesario el elaborar una nueva teoría del contrato agrario ${ }^{16}$.

Pero son diversos los autores y de distintos países los que se han ocupado del "contrato agrario" para tratar de establecer sus principios, al igual que lo hiciera BOLLA ${ }^{17}$ con dicho concepto y los "los principios sobre los cuales se basa y disciplina la institución autónoma de los contratos que interesan a la agricultura" y coincidiendo en el tiempo, también, aunque en distinta latitud el Profesor RIVOLA utilizó la voz acorde en la Ley, el concepto genérico que abarque todas las convenciones jurídicas actuales de la explotación rural ."que es característica más precisa que la de uso y goce".

\footnotetext{
${ }^{15}$ CARROZZA.A. "Estratto dall'apendice del novisimo digestio italiano". Ediciones Utet. Turin.198, pag.7 y GOLDONI, M." La nozione di contratto agrario. ETS. Ed. Pisa.1988.pag, 221 Ambos ponen de manifiesto como la doctrina duda sobre la existencia del contrato agrario.

${ }^{16}$ En este sentido el Profesor DE LOS MOZOS J.L. en Estudios de Derecho Agrario. Editorial Tecnos., Madrid, 1972. pag. 264- 266. Entiende que sólo tiene sentdio hablar de contratos agrarios cuando este planteamiento se hace desde el Derecho Civil o si se prefiere desde lo que llamaos Derecho Civil Agrario, porque aunque el tema se desenvuelva en gran parte en el marco del Derecho de reforma de la agricultura y aún en el Derecho de la empresa agraria, sólo desde este punto de vista aparece clara la finalidad de tales contratos como contratos que se refieren "a la agricultura como actividad", añadiendo posteriormente, la problematica que plantea y responden los contratos agrarios es en cierto modo, una problemática permanente, que pone de relieve las profundas raíces civilistas del Derecho agrario.

17 "Contrato Agrario" en Nuovo Digesto I, Torino 1938
} 
Los contratos agrarios no pretenden desgajarse totalmente de la teoría general del contrato $^{18}$ y han de partir de ella y de sus principios fundamentales, pero constituyen una clase especifica de contratos distintos y separados de los demás por unos caracteres que le son propios por lo acusado de determinadas notas del ámbito que regulan, la materia agraria, y en definitiva, por afectar a un interés vital como es la agricultura y constituir ésta el objeto genérico de su profusa regulación especial actual.

Al tratarse de "contratos" debe aplicarse la doctrina general del contrato y las disposiciones que con carácter general establecen los Código civiles o mercantiles para todo tipo de contratos, y en todo aquello que no está modificado por leyes especiales agrarias. Bien entendido que los contratos agrarios han existido "de hecho" desde hace tiempo, en este sentido el Profesor DE LA CUESTA ${ }^{19}$ opina que los contratos agrarios "deben su configuración básicamente al Derecho Romano del que han recibido incluso su antigua denominación en muchos ordenamientos modernos, por lo que puede decirse que albergan lo más antiguo y permanente de una disciplina que, como la jurídico- agraria no se caracteriza precisamente por su vetustez y estabilidad"; En este sentido cabe destacar que el Código Civil somete a los contratos agrarios al régimen jurídico que del resto de los contratos en el mismo cuerpo legal. Será en los años 30 cuando se comienza a dar pasos de desvinculación de estos contratos del Código Civil a través de leyes especiales quebrando la concepción jurídica en la que la agricultura se encontraba.

En el Código civil no encontramos la definición de contrato, ni tampoco aquella referida al contrato agrario, quizás, como señala el Profesor SANCHEZ HERNANDEZ ${ }^{20}$ porque se presupone. Ausencia que deberemos suplir acudiendo a la formulada por los distintos autores, en este sentido el mismo, el autor ${ }^{21}$, define el contrato agrario como aquel cuya finalidad típica es la obtención de un rendimiento económico mediante la atribución de una titularidad de aprovechamiento de los bienes destinándolos a la producción agrícola, silvícola o ganadera con fines de mercado. Y el

\footnotetext{
18 DOMENECH MARTINEZ, G.. Los contratos de integración agroindustrial. Ediciones Cooperativas. Buenos Aires.2010,pag, 37

19 "Contratos Agrarios", Actas del II Congreso Europeo y I Iberoamenricano de Derecho Agrario, Servicio de Publicaciones de la Universidad de Almeria, 1998, p. 115.

20 SANCHEZ HERNANDEZ, A. En "El contrato Agrario" El Derecho Agrario: Modernización y Desarrollo Rural . Tiran lo Blanc.,2001, pag. 148 y 149 . Y del mismo autor en "Clasificación Básica de los Contratos Agrarios". Manual de Instituciones de Derecho Agroambiental Euro-Latinoamenricano, pág. 232.

${ }^{21}$ Obra citada, pag. 219
} 
Profesor LUNA SERRANO ${ }^{22}$ los definirá como aquellos en los que las partes interesadas persiguen como finalidad típica el aprovechamiento económico de los bienes agrarios fructíferos mediante la atribución de una titularidad de explotación que supone el destino duradero de los bienes a la producción agrícola, silvícola o ganadera. Ambas definiciones son semejantes.

Desde otra perspectiva, para el Profesor DE LA CUESTA ${ }^{23}$, el concepto de empresa viene a tener una menor importancia en materia de contratos agrarios, lo que resulta más acorde con su origen histórico y con los desarrollos más recientes del Derecho Agrario Comunitario, en concreto, con la retirada de tierras.

En la doctrina latinoamericana, acorde con las experiencias de su propio ámbito territorial, también se ha procedido a elaborar una definición de contratos agrícolas, entre ellos cabe citar, al Profesor BREBBIA ${ }^{24}$ al definiros como "son contratos agrarios aquellos cuya función consiste en construir una empresa y reglar su funcionamiento. Son también contratos agrarios aquellos en los que siendo una de la partes un empresario agrario, tienen por finalidad servir al funcionamiento de una empresa agraria ya constituida y funcionando" y al Profesor PASTORINO ${ }^{25}$

Nosotros, hace algunos años, ya pergeñamos una definición en los siguientes términos "convenio o consenso entre dos o más personas, físicas o jurídicas vinculadas al sector agrario, a través del cual deciden en obligarse recíprocamente a dar alguna cosa o prestar algún servicio cuyo destino es la producción y la comercialización agraria"26

\section{III.2.- Las distintas clasificaciones del contrato agrario}

Como señalábamos anteriormente existen, muchos autores, tanto españoles, como extranjeros que han estudiado de forma individual los contratos agrarios, por ejemplo la "messadria", el arrendamiento, etc..., pero no existe unanimidad en la enumeración de los diferentes contratos agrarios. Los autores que se han preocupado de su clasificación lo hacen según orientaciones muy diversas y proponen criterios heterogéneos.

\footnotetext{
${ }^{22}$ LUNA SERRANO, A. En Rivista de Dirrito Agrario, 1975, núm. 4, pág. 592.

${ }^{23}$ DE LA CUESTA, J.M en su Comunicación al II Congreso Europeo y I Iberoamenricano de Dereccho Agrario, Almería 1997, pag. 117.

${ }^{24}$ BREBBIA, Anteproyecto de la Ley General de Contratos Agrarios Argentina.

${ }^{25}$ PASTORINO, L.F. Derecho Agrario Argentino, Abeledo Perrot, Buenos Aires, 2009, pag.447

${ }^{26}$ DOMENECH G. Los Contratos de integración agroindustrial. Ediciones Cooperativa. Buenos Aires, 20, pag.79.
} 
Entre los agraristas de nuestro país no suelen encontrarse clasificaciones de los contratos, no obstante y sin ánimo exhaustivo, expondremos algunas de ellas. En algún caso, como lo hizo el Profesor MARTIN BALLESTERO Y COSTEA ${ }^{27}$ los enumera, reseñando los siguientes tipos: Los censos consignativos la enfiteusis, los arrendamientos rústicos, la aparcería, el trabajo agrícola, el colonato, los contratos de tipo asociativo, los de ventas de frutos (comprendiendo la "empetio Spei" de frutas y cosechas) los contratos derivados de la concentración parcelaria, la permuta forzosa de finca rústicas, los retractos, los contrato de mejoras de fincas rústicas y algunos recogidos en las compilaciones forales (por ejemplo: los pactos sucesorios encaminados a mantener la unidad de la explotación familiar agraria).

Por su parte, el Profesor SANZ JARQUE ${ }^{28}$ propone una ordenación en grupos de contratos agrarios, en relación:

1.-Con el sistema de tenencia: arrendamientos, aparcerías, compraventa de inmuebles rústicos.

2.- Con los sujetos.

3.- Con el objeto: créditos, mejoras (contratos ad meliorandum)

4.- Con el contenido: compraventa de productos agrarios, acciones concertadas, consorcios, etc.

5.- Con la organización de empresa: de integración, de participación.

6.- Con la reforma de estructuras agraria: arrendamientos rústicos forzosos, permuta forzosa y concesión de tierras.

El Profesor DE LA CUESTA ${ }^{29}$, conviniendo que la causa del contrato agrario no es la empresa, ni la finalidad de política social que la legislación especial ha podido en algunos momentos acentuar; aboga por una clasificación de los contratos agrarios en sentido estricto, con una base más civilista, y contrapone por una parte a los contratos de cambio (arrendamiento por ejemplo), con los asociativos (en nuestro derecho las

\footnotetext{
27 Teoría general del contrato agrario en Rivista de Dirito Agrario Casa Editrice Dott. A. Giuffrè Milano, 1971, pág. 324 y sig.

${ }^{28}$ Obra. Cit. pág. 171

${ }^{29}$ Comunicación al II Congreso Europeo y I Iberoamericano de Derecho Agrario, Almería, 1997, pág. 117 y 118.
} 
sociedades Civiles y mercantiles, cooperativas y SATS), ampliando este elenco con contratos de concesión en sentido estricto (censos, algunos contratos agroindustriales) y mixtos en los que alguna de las partes o todas aportan su trabajo (aparcería). Los contratos agrarios, en sentido amplio, y relacionado necesariamente con la noción de empresa, dirá este autor, estarían los contratos "de la empresa", de la hacienda agraria y que son una larga lista de figuras típicas y atípicas. Como son el contrato de trabajo, el de mutuo, el de seguro, el leasing, las concesiones de riego, las sociedades de servicio, las agrupaciones de productores y el resto de los contratos agroindustriales no incluidos entre los de concesión.

La dificultad que entraña la clasificación de los contratos, la justifica el Profesor SÁNCHEZ HÉRNANDEZ ${ }^{30}$, señalando como botón de muestra la ausencia de unanimidad entre los autores a la hora de enumerar los diferentes contratos agrarios. Consecuente con dichas manifestaciones, el Profesor de La Rioja, nos ofrece un doble listado:

1.- En el primero de ellos se agrupa los contratos que según su propia definición, encajan en la estructura del contrato agrario, ubicando en éste: el arrendamiento rústico, la aparcería agraria, la enfiteusis, la cooperativa de explotación comunitaria de la tierra, $\mathrm{y}$, por último, los contratos atípicos, dentro de los cuales considera incluidos los contratos "ad meliorandum" y el contrato destinado al engorde de ganado por medio de pastoreo; Y,

2.- En un segundo listado, aquellos que han sido considerados por algún sector doctrinal como tales, pero que a su juicio no guardan la estructura del contrato agrario defendido. Contemplando en este segundo listado la compraventa de predios y frutos ${ }^{31}$, los censos,

\footnotetext{
${ }^{30}$ SANCHÉZ HERNANDÉZ, ANGEL. En "El contrato Agrario", El Derecho Agrario: Modernización y Desarrollo Rural, Tirant lo Blanc, 2001, págs. 183 y 184 y del mismo autor en "Clasificación Básica de los Contratos Agrario", Manual de Instituciones de Derecho Agroambiental Euro-Latinoamericano, págs. 249 y 250.

${ }^{31}$ Resulta interesante las particularidades que el autor señala para determinar la exclusión del carácter de contrato agrario, cuando el agricultor celebrada la venta del producto sólo se vea constreñido a permitir la entrada para la recolección del fruto determinando la exclusión del carácter de contrato agrario dependiendo o no, si una vez vendida la cosecha. SANCHÉZ HERNANDÉZ, ANGEL. En "El contrato Agrario", El Derecho Agrario: Modernización y Desarrollo Rural, Tirant lo Blanc, 2001, páginas 196 y 201. Y del mismo autor en "Clasificación Básica de los Contratos Agrarios", Manual de Instituciones de Derecho Agroambiental Euro-Latinoamericano, págs. 259 y 265.
} 
la permuta de finca rústica, el crédito agrario, el seguro agrario, los contratos agroindustriales, la retirada de tierras de cultivo, etc.

\section{III.3.- Los elementos del contrato de gestión y planificación de la producción}

Como ya hemos señalado, el contrato agrario tiene como base y punto de partida la doctrina contractual del Derecho Civil, y se asienta sobre los sólidos pilares del Derecho Común de los contratos contenidos en el mismo.

Consecuentemente, el contrato agrario necesita partir de los principios fundamentales de la teoría general del contrato.

En el Derecho Positivo Español al referirnos a la regulación general de los contratos, debemos acudir al Título II, Libro IV de nuestro Código Civil, que en sus artículos 1254 a 1314, comprenden el cuerpo esencial de la regulación general de los contratos y la del tipo contractual. Este conjunto de disposiciones constituye las normas generales en las que el legislador plasma lo que entiende por contrato, se trata en buena parte derecho imperativo y regulación básica que abarca a todas las concretas regulaciones contractuales.

En nuestro Código Civil no se contiene una definición de contrato .Esta ausencia la justifica el profesor DIEZ-PICAZO"32 por no ser la " función del legislador la de proporcionar definiciones doctrinales y acaso también por presuponer el concepto vigente en el momento de su redacción”.

No obstante, el legislador nos ha facilitado su concepto a través del contenido de varios de sus artículos de cuyo ensamblaje podemos averiguar la idea que del contrato tuvieron los autores de este cuerpo legal. De entre ellos, destacamos los siguientes:

a).- En el art. 1089 C.c., se menciona al contrato como fuente de las obligaciones... "Son fuentes de las obligaciones los contratos, cuasi contratos...”.

b).- En el art. 1091 C.c., se afirma que "las obligaciones que nacen de los contratos tienen fuerza de ley entre las partes contratantes y deben cumplirse a tenor de los mismos".

\footnotetext{
32 DIEZ-PICAZO, L. En Fundamentos del Derecho Civil Patrimonial, Vol. I Introducción, Teoría del Contrato, Las relaciones Obligatorias, Editorial Tecnos, $3^{\text {a }}$ edición 1979
} 
c).- En el art. 1254 C.c., más que expresar su naturaleza jurídica, su verdadera intención parece que fuera señalar el momento de su nacimiento o perfección. En el mencionado artículo se destaca que "El contrato existe desde que una o varias personas consienten en obligarse, respecto de otra u otras, a dar alguna cosa o prestar algún servicio". Se menciona de un lado, el consentimiento en común de dos o más personas (ya sean físicas o jurídicas), por otro, la finalidad, esto es la creación de unos vínculos jurídicos entre las partes, el objeto de la prestación: cosas o servicios.

Indirectamente del mencionado art. 1.254 del C.c., se desprende que se acepta la concepción estricta u obligacional del contrato, circunscribiéndolo a las relaciones patrimoniales, y considerándolo como una convención o acuerdo de voluntades para la creación de una obligación de dar o hacer ${ }^{33}$ En este sentido, DE BUEN ${ }^{34}$ señalará: "los términos del artículo 1254 del Código Civil revelan que en el pensamiento del Código el ámbito de la contratación es el de los derechos de crédito y el de los derechos reales, puesto que, según dicho artículo, en todo contrato la obligación consiste en dar alguna cosa".

Pero en la concepción moderna del contrato, debemos destacar como imprescindible, de todo lo estudiado, las notas siguientes:

1.- El carácter de fuerza de ley que tiene entre las partes.

2.- Su existencia dependerá exclusivamente de la voluntad de los intervinientes.

3.- Es el origen de una o varias obligaciones para cada una de las partes que intervienen.

4.- Las obligaciones que surgen para cada una de las partes, no son de una única naturaleza, sino que varian según la causa (producir bienes vivos, en el cado de los contratos agrarios).

Además de lo anteriormente destacado, entendemos que el contrato tiene su más profunda raíz y su más profundo fundamento en una serie de presupuestos ideológicos y sociológicos $^{35}$ que como señala el Profesor DIEZ PICAZO, conviene tener en cuenta y no perder de vista en el momento jurídico actual.

\footnotetext{
${ }^{33}$ Derecho Civil Español y foral. Tomo III J. CASTÁN TOBEÑAS, pág. 444

${ }^{34}$ Notas al curso de Colin y Capitán Tomo III, pág. 532

${ }^{35}$ DIEZ-PICAZO, En El Concepto de Contrato y su Esfera de Aplicación, páginas 88 y 89.
} 
Por todo ello se entiende por contrato "el acuerdo de voluntades entre dos o más personas que origina derechos y obligaciones entre ellas".

Además, en esta materia rige el llamado principio de autonomía de la voluntad privada que es el instrumento técnico jurídico de la colaboración económica entre las personas, contenido en el art. 1255 del Código Civil que predica la facultad de los contratantes para establecer los pactos, las cláusulas y condiciones que tengan por conveniente, siempre que no sean contrarios a las leyes, la moral o al orden público. El tenor liberal de dicho artículo es reflejo de la libertad de pacto, tan tradicional en el Derecho Español, desde el Ordenamiento de 1348, en cuya filosofía se inspiro dicho artículo al mantener que "Los contratantes pueden establecer los pactos, cláusulas y condiciones que tengan por conveniente, siempre que no sean contrarios a las leyes, a la moral, ni al orden público".

Consecuentemente, los pactos, cláusulas y condiciones contenidas en el acuerdo suscrito por la Cooperativa pueden ser aquellos que se estimen convenientes, sin restricciones en aras al interés general por parte de la Administración Pública.

Será objeto de nuestra atención los elementos necesarios para la existencia de dicho contrato, preceptuados en el art. 1.261 del C.c., al negar su existencia si no se dan los requisitos del consentimiento, objeto y causa, como elementos esenciales, por lo que la ausencia de uno de ellos imposibilita el nacimiento de la relación contractual. Además, de otros requisitos de validez, como son la capacidad de los contratantes, art. 1265 del mismo cuerpo legal, y la ausencia de vicios del consentimiento, art. 1265 de dicha normas sustantiva.

Elementos que vamos a analizar a través de su especialidad en el acuerdo objeto de nuestro interés.

\section{III.3.a.- El consentimiento}

El consentimiento es requisito primordial en todo tipo de contrato. Es el acuerdo de los contratantes, consistente en la coincidencia de dos o más voluntades. Sabemos que es requisito primordial del contrato en general y de los agrarios en particular, el acuerdo de los contratantes, consistente en la coincidencia de dos o más voluntades. El art. 1.262 del C.c. lo define "como el concurso de la oferta y de la aceptación sobre la cosa y la causa que han de constituir el contrato", esto es, hacer concordar voluntariamente la 
oferta y la aceptación sobre el contenido del contrato, acuerdo que es recíproco consenso representado en la convergencia de la voluntad individual de los contratantes $^{36}$. RUGGIERO lo define como "el encuentro de dos declaraciones de voluntad, que partiendo de dos sujetos diversos se dirigen a un fin común y se unen".

El Código de Napoleón, antecedente de nuestro Código Civil, se elaboró bajo la influencia de la filosofía iusnaturalista. Es por ello que el contrato consiste esencialmente en el acuerdo de voluntades. Autonomía de la voluntad en la que se fundamenta la fuerza obligacional del contrato. La autonomía privada de la voluntad, se refiere a "la posición de poder en que se halla un sujeto para determinar por sí mismo sus relaciones jurídicas con los otros sujetos mediante el ejercicio de su libertad y dentro de los confines de lo lícito" 37 .

Y al mismo tiempo que otros requisitos de validez, como son la capacidad de los contratantes (art. 1.263 del C.c), y la ausencia de vicios de consentimiento (artículo 1.265 del mismo cuerpo legal).

En cuanto a la capacidad de las partes para celebrar un contrato agrario podemos referirla tanto a la capacidad legal, como a la capacidad técnica exigida a las partes para celebrar un contrato agrario.

a).- La capacidad legal para contratar, que es la de obrar, de las partes contratantes. Se trata de una condición necesaria para la existencia del consentimiento. Sin dicha capacidad de obrar no se puede prestar el consentimiento de forma válida, es por ello que en el art. 1263 del Ccv. se enumera aquellas personas, que no pueden prestar su consentimiento señalando en tal sentido: a los menores no emancipado y los incapacitados, dado que no disponen de una capacidad de obrar plena.

La voluntad necesaria para prestar consentimiento, ha de ser consciente y libre. Será nulo el consentimiento prestado con error, violencia, intimidación o dolo.

b).- Otro ámbito distinto ofrece el de la idoneidad técnica de dicha capacidad, pues al menos una de las partes que interviene en el contrato agrario deberá ser empresario, o

\footnotetext{
${ }^{36}$ GALGANO F. El Negocio Jurídico, Traducción realizada por Blasco Gascó y Prats Albentosa, Tirant lo Blanc, Valencia, 1992, pág. 83 y sig.

${ }^{37}$ MELICH ORISNI, J. Doctrina General del Contrato, $3^{\mathrm{a}}$ Edc. Marcial Pons, Caracas, 1997, p .37
} 
sea, realizará una actividad dirigida hacia la producción agraria. Esa idoneidad, la denominamos, siguiendo al Profesor SANCHEZ ${ }^{38}$ como idoneidad técnica.

Pero no sólo podemos considerar profesionales de la agricultura a los efectos de su capacidad para contratar, a las personas físicas; también lo son las jurídicas, y entre ellas podemos señalar como ejemplo a las cooperativas de explotación comunitaria de la tierra o de trabajo asociado; las sociedades agrarias de transformación y otras sociedades siempre que tengan por exclusivo objeto, conforme a sus Estatutos, el ejercicio de la actividad agraria, y siempre que sus acciones o participaciones sean nominativas.

En este sentido, en nuestro modelo, al ser una de las partes una cooperativa agraria, la Cooperativa, el carácter de agrario de dicho instrumento queda acreditado. Cualidad irrefutable si la misma actúa explícitamente a través de su sección hortofrutícola, despejando cualquier tipo de duda sobre su cualidad de "agrícola".

\section{III.3.b.- El objeto}

Este elemento esencial en el contrato se regula en concreto en el art. 1271 del Ccv., disciplinando que pueden serlo todos los servicios lícitos y todas las cosas que no estén fuera del comercio de los hombres, aún las futuras. Añade, el artículo siguiente, el 1272 que no podrán ser objeto del contrato las cosas y servicios imposibles, o sea aquellas que no pueden llegar a existir o no pueden alcanzarse "No podrán ser objeto de contrato las cosas o servicios imposibles". Continuando la regulación del objeto del contrato en el artículo 1273 que "el objeto de todo contrato debe ser una cosa determinada en cuanto a su especie. La indeterminación en la cantidad no será obstáculo para la existencia del contrato, siempre que sea posible determinarla sin necesidad de nuevo convenio entre las partes contratantes".

Pero hemos de matizar, que si el contrato es el medio adecuado para que los sujetos que intervienen elijan sus propias obligaciones, podemos determinar que de un contrato surgen efectos que consisten en la producción de obligaciones. Son las obligaciones las

38 Término "idoneidad técnica" que es utilizado por SÁNCHEZ HERNÁNDEZ, A. en El Derecho Agrario: Modernización y Desarrollo Rural, pág. 159. Y del mism0o autor, en "Clasificación Básica de los Contratos Agrario", Manual de Instituciones de Derecho Agroambiental Euro-Latinoamericano, pág. 228. 
que tienen un objeto. La doctrina no ha confundido el objeto del contrato con el objeto de la obligación ${ }^{39}$.

Si la prestación se considera objeto del contrato es, entre otras cosas, para juzgar la misma validez del contrato en virtud de lo dispuesto en el artículo 1.271 de nuestro Código Civil, es decir, la exigencia de la comercialidad de las "cosas" o de la posibilidad de las "cosas o servicios" 40 .

Según el C.cv, ha de entenderse por objeto del contrato la cosa, el derecho real o crediticio que el contrato transfiere de una parte a la otra, o bien, la prestación que una parte se obliga a ejecutar a favor de la otra ${ }^{41}$. Se trata de la cosa que se debe dar o aquello que se debe hacer o no hacer. En esta misma línea argumental se encuentra la jurisprudencia que explica el objeto del contrato como "aquella realidad sobre la que el contrato incide y en relación a la que recae el interés de las partes o la intención negocial o el móvil esencial del contrato, es decir, el comportamiento a que el vínculo obligatorio sujeta al deudor y que tiene derecho a exigir el acreedor ${ }^{\star 42}$.

La diferencia entre objeto y causa del contrato es una relación de medio a fin. Esto es, el objeto consiste en las "cosas" o en las prestaciones mediante las cuales se realiza la función o el fin económico-social del contrato, que es la causa ${ }^{43}$.

En la especialidad del contrato al que nos estamos refiriendo, el objeto de contrato agrario es la explotación agraria ${ }^{44}$. Circunstancias que expresamente se recoge en nuestro derecho positivo, en el artículo 2.2. de la Ley 19/95 de 4 de julio de Modernización de Explotaciones Agrarias, nos encontramos claramente con una descripción de un bien complejo, que puede tener un tratamiento unitario, esto es, ser objeto único de un contrato, en este precepto se define la explotación agraria como "el

\footnotetext{
${ }^{39}$ DE LOS MOZOS, "El Objeto del Negocio Jurídico", en Revista de Derecho Privado, 1960, p. 372,

${ }^{40}$ SÁNCHEZ HERNÁNDEZ, A. En "El contrato Agrario" página 164, en Derecho Agrario: Modernización y Desarrollo Rural, Tirant Lo Blanc, 2001. Y del mism0o autor, en "Clasificación Básica de los Contratos Agrario", Manual de Instituciones de Derecho Agroambiental Euro-Latinoamericano, pág. 232.

${ }^{41}$ GALGANO, F., El Negocio Jurídico. Trad. Blasco Gasco y Prats Albentosa, Tiran Lo Blanc, Valencia, 1992, Pág. 123.

${ }^{42}$ Sentencia, entre otras, del Tribunal Supremo de 5 junio de 1978.

${ }^{43}$ SÁNCHEZ HERNÁNDEZ, A. En "El contrato agrario", pág. 164, en Derecho Agrario: Modernización y Desarrollo Rural, Tirant lo Blanc, 2001. Y del mism0o autor, en "Clasificación Básica de los Contratos Agrario", Manual de Instituciones de Derecho Agroambiental Euro-Latinoamericano, pág. 232.

${ }^{44}$ AMAT LLOMBART.P. "La explotación agraria, sus elementos integrantes y tipos cualificados de explotación. La reforma legislativa pendiente" Tratado de Derecho Agrario..(Muñiz Espada E y Amat Llombart,P Direct).Wolters Kluwer 2017 pág. 157.
} 
conjunto de bienes y derechos organizados empresarialmente por su titular en el ejercicio de la actividad agraria, primordialmente con fines de mercado, y que constituye en sí misma una unidad técnico-económica".

También, en la legislación hipotecaria se describe la explotación agraria como un bien complejo, en concreto en el Artículo 8.2.2 $2^{45}$ " "Toda explotación agrícola, con o sin casa de labor, que forme una unidad orgánica, aunque esté constituida por predios no colindantes, y las explotaciones industriales que formen un cuerpo de bienes unidos o dependientes entre sí." Asímismo, en el art. 44 del Reglamento Hipotecario se recoge una descripción en estos términos: "Se inscribirán bajo un solo número, si los interesados lo solicitaren, considerándose como una sola finca con arreglo al artículo octavo de la Ley y para los efectos que el mismo expresa, siempre que pertenezca a un solo dueño o varios proindiviso(...) 3. ${ }^{\circ}$ Los cortijos, haciendas, labores, masías, dehesas, cercados, torres, caseríos, granjas, lugares, casales, cabañas y otras propiedades análogas que formen un cuerpo de bienes dependientes o unidos con uno o más edificios y una o varias piezas de terreno, con arbolado o sin él, aunque no linden entre sí ni con el edificio, y con tal de que en este caso haya unidad orgánica de explotación o se trate de un edificio de importancia al cual estén subordinadas las fincas o construcciones. $4 .^{\circ}$ Las explotaciones agrícolas, aunque no tengan casa de labor y estén constituidas por predios no colindantes, siempre que formen una unidad orgánica, con nombre propio, que sirva para diferenciarlas y una organización económica que no sea la puramente individual, así como las explotaciones familiares agrarias."

Al referirse a explotación agrícola, se hace referencia a una unidad de destino a la que pueden estar vinculadas una, dos, o más fincas, siempre bajo un solo dominio y gestión.

Expresamente, en dicho documentos existe una referencia explícita a cada una de las fincas incluidas, en su caso, que deberán identificarse a través del SIGNAP ${ }^{46}$ de forma individualizada por su vinculación con uno de los elementos esenciales del contrato, y

\footnotetext{
${ }^{45}$ Decreto de 8 de febrero de 1946, por el que se aprueba la nueva redacción oficial de la Ley Hipotecaria.. Vigencia desde 31 de Diciembre de 1946. Revisión vigente desde 06 de Diciembre de 2015, que ha mantenido la redacción anterior.

${ }^{46}$ Real Decreto 1077/2014, de 19 de diciembre, por el que se regula el sistema de información geográfica de parcelas agrícolas, BOE Núm. 307, 20 de diciembre de 2014.
} 
además, como luego se dirá, por ser uno de los requisitos necesarios para la posible cesión de los derechos derivados de la $\mathrm{PAC}^{47}$.

Además, sería aconsejable añadir una nota simple, para acreditar la inexistencia de carga o gravamen sobre la misma, por su escasa repercusión económica que la misma puede tener y lo valioso de la información que puede aportar al negocio jurídico de que se trata.

Calificados los contratos agrarios en especial por su objeto, la citada dimensión agraria impone tener en cuenta a su vez para su clasificación los fines agrarios a los que tiende el negocio jurídico, que se convierte en especial, por razón, no solo de los sujetos y del objeto, sino de los fines a los que dichas relaciones jurídicas están dirigidas: el potenciar el ejercicio de la actividad agraria. Circunstancia que en nuestro modelo se contiene con claridad meridiana

\section{III.3.c.- La causa "especial de los contratos agrarios.}

El concepto de "causa" dentro de la teoría de los contratos es uno de los conceptos más difíciles de la doctrina y de la técnica del Derecho Civil.

Es a partir del Código de Napoleón cuando la idea de causa se convierte en elemento normativo, y en un requisito legal de validez de los contratos, debemos entender por causa la razón de ser del contrato. Se toma en consideración a fin de controlar la conformidad del contrato a los objetivos o finalidades establecidas por la Ley y en relación a los contratos agrarios, se verifica así la conformidad del uso que se hace del instrumento contractual diseñado por el legislador en ejecución de una determinada política agraria $^{48}$.

Una de las posibilidades de interpretar la causa ${ }^{49}$, en los contratos, es, en primer lugar, la de considerar el fin que el mismo persigue como los motivos o intereses que impulsan a las partes a contratar. Y en segundo lugar la basada en la idea de causa objetiva. La

\footnotetext{
${ }^{47}$ Para cesiones referidas al régimen de pago básico y al régimen simplificado para pequeños agricultores. 48 SÁNCHEZ HERNÁNDEZ, A. En "El contrato Agrario" Derecho Agrario: Organización y Desarrollo Rural. Pág. 169, Tirant Lo Blanc 2001. Y del mismo autor en "Clasificación Básica de los Contratos Agrario”, Manual de Instituciones de Derecho Agroambiental Euro-Latinoamericano, pág. 236.

49 Esta segunda corriente doctrinal entiende la causa como fin del contrato. La jurisprudencia francesa había encontrado insuficiente muchas veces la antigua teoría para proteger la moralidad de las relaciones jurídicas y descendió, por ello, en ocasiones a examinar la intención concreta perseguida por las partes al realizar el negocio, el propósito específico que las ha guiado para celebrarlo. A este propósito y a esta intención se llamará causa.
} 
dirección objetivista, entiende la causa como función económico-social. La "razón del negocio" es su "función económico-social. El negocio, como acto de ejercicio de la autonomía privada, es ante todo un fenómeno social. Lo que hay que buscar entonces es la función típica de este fenómeno social que es lo que el derecho valora y tutela hasta el punto de elevarlo a la categoría de fenómeno jurídico preceptivo para sus autores. La causa, razón o justificación objetiva del negocio se encuentra en su función.

En nuestro Código Civil, entiende la doctrina responde fundamentalmente a la orientación objetiva. Es la razón de ser del contrato, el fin generalizador y objetivo que se proponen las partes al contratar. Y en este sentido el artículo 1274 de nuestra Ley Sustantiva Civil, sigue esta dirección.

Es un requisito general y como expresa el artículo 1.277 "aunque la causa no se exprese en el contrato se presume que existe y que es lícita mientras el deudor no pruebe lo contrario". Los requisitos de la causa aluden:

En primer lugar, a la necesidad de su existencia, dado que los contratos sin causa no producen efecto alguno (el art. 1275.1). Pero no hace falta que esté expresa en el contrato, pues se presume que existe la causa mientras el deudor no pruebe lo contrario (art. 1.277 del C.c.).

En segundo término, ha de ser verdadera (art. 1.276 del C.c.) "la expresión de una causa falsa en los contratos dará lugar a la nulidad si no se probase que estaban fundados en otra verdadera y lícita”.

En tercer lugar, la causa ha de ser lícita. Es ilícita la que se opone a las leyes o a la moral y conlleva la inexistencia del contrato (art. 1275 del C.c.). Pero se presume la licitud mientras no se pruebe lo contrario.

Como hemos señalado y a tenor del contenido del art. 1.274 del C.c., existen tres tipos de causa: onerosa, remuneratoria y gratuita.

Sin embargo, en el derecho Español, no puede afirmarse, como hace la doctrina italiana, que los contratos agrarios tienen como causa única y universal la de ser concertados por y para la empresa agraria ${ }^{50}$.

\footnotetext{
${ }^{50}$ En la Doctrina Italiana, por algunos autores así se contempla.
} 
El contrato agrario tiene un objetivo o un fin que incide en su específica relevancia jurídica. Pensemos en un crédito agrario destinado a permitir la compra de animales para su engorde, sin embargo se desliga del contrato directamente relacionado con la empresa, que es el contrato de integración. En caso de anularse el contrato de integración, no puede predicarse la anulación del crédito del ganadero. La causa del contrato de crédito agrícola reside en poner a disposición del ganadero los fondos necesarios para adquirir las cabezas de ganado prevista. Consecuentemente, no concluido el contrato de integración deja subsistente la causa del contrato de crédito. Este objetivo o fin será el que nos permite otorgarle una sustantividad ${ }^{51}$, de la que no gozaría en otro tipo de ordenamiento jurídico. Por ejemplo, los llamados contratos en cadena del derecho alemán(Kettenverträge)

La razón de los contratantes como determinante de la voluntad contractual consiste en "la atribución de la titularidad del aprovechamiento económico de unos bienes en función de su destino productivo agrario". En nuestro caso concreto la atribución del aprovechamiento de una explotación agraria en función de su destino a la producción de cítricos.

La naturaleza típica de los intereses de la producción agraria con los que el contrato resulta vinculado, provoca en él una disciplina diferenciada de tutela jurídica que justifica el desplazamiento patrimonial, no olvidemos que el contrato agrario responde en su regulación a una realidad operativa diferente de la cual extrae su individualidad: los intereses agrarios que se aprecian de manera relevante en el tipo de conflicto que resuelve el negocio jurídico ${ }^{52}$.

\section{III.3.d.- La forma}

Como sabemos, en nuestro derecho la forma del contrato es libre desde que se proclamara por primera vez en el Ordenamiento de Alcalá en el año 1348. Tradición en nuestro derecho patrio de modo que los contratos obligan a las partes contratantes de cualquier modo que se celebren siempre que en ellos concurran los elementos esenciales

\footnotetext{
51 MARTIN BALleStero Y COSTEA, Teoría Generale del Contratto Agrario, Rivista di Diritto Agrario, anno 1971, pág. 338.

52 GUERRA DANERI, E. En "Bases de la Calificación del contrato Agrario". Revista Argentina de Derecho Agrario, año, 3, núm. 4 septiembre de 1994, p. 42 y en este mismo sentido el Profesor “ SANCHÉZ HERNÁNDEZ A. En "El contrato Agrario" Derecho Agrario: Organización y Desarrollo Rural. Pág. 170. Y del mismo autor en "Clasificación Básica de los Contratos Agrario", Manual de Instituciones de Derecho Agroambiental Euro-Latinoamericano, pág. 237.
} 
para su validez, según el artículo 1278 del C.c. preceptúa "Los contratos serán obligatorios, cualquiera que sea la forma en la que se hayan celebrado, siempre que en ellos concurran las condiciones esenciales para su validez".

Como regla general hemos de señalar que la forma no es requisito esencial del contrato. Pero, en nuestro Derecho esta regla general tiene excepciones: se exige forma solemne para la perfección de ciertos contratos, que suelen ser la exigencia del documento público, Escritura Pública y hasta inscripción en el Registro de la Propiedad; en otras ocasiones se exige una forma solemne no para su validez, sino a efectos de probar su existencia ante terceros, entre ellos podemos citar, el artículo 1.280 del C.c., en el que se señala dicha forma solemne para "los actos y contratos que tengan por objeto la creación, transmisión, modificación o extinción de derechos reales sobre bienes inmuebles".

Dentro de estas excepciones hemos de hacer referencia, como ejemplo, a la Ley Extremeña de Modernización y Mejora de las Estructuras de las Tierras de Regadío, de 26 de noviembre de 1992, que impone en su art. 19 el requisito del otorgamiento de escritura pública e inscripción en el Registro de la Propiedad para la perfección de la transmisión de una explotación agraria, términos estos inadecuadamente empleados pues el propio precepto aclara su limitado alcance al exigir los requisitos mencionados, tan sólo "a los efectos de esta Ley", es decir, para beneficiarse de las ayudas que en dicha Ley se establece. La exigencia de forma escrita también se exige en el artículo 17 de la Ley citada que la impone a los contratos de arrendamiento de las fincas rústicas.

Y en la Ley Extremeña de Caza se ordena que todo arrendamiento, cesión o contratación de terrenos o de puestos y permisos de caza, deberá formalizarse por escrito y someterse al visado de la agencia. No obstante, la Sentencia del Tribunal Constitucional de 22 enero de $1998^{53}$, matizó el alcance de la norma, considerando que dicha exigencia formal únicamente tiene efectos en las relaciones con la Administración Autonómica, lo que permite inferir que, a efectos civiles será válido el contrato verbal que obligaría a las partes contratantes aunque no causará efectos en relación al posible cobro de subvenciones o de obtención de autorizaciones administrativas.

Consecuentemente, en el presente modelo de la Cooperativa no es necesario que el mismo conste en instrumento público como requisito para su validez. No obstante,

\footnotetext{
${ }^{53}$ Sentencia no 15/1998 de Tribunal Constitucional, Pleno, 22 de Enero de 1998
} 
desde estas líneas, en términos de seguridad en el trafico jurídico, postulamos, en aras a la seguridad del tráfico jurídico, plasmar por escrito el contenido del clausurado en un instrumento público. Además, como fórmula de publicidad frente a terceros su inscripción en el Registro de la Propiedad correspondiente. Todo ello para proteger los acuerdos contenidos en dicho instrumento con un plus, dada la fe pública y la protección frente a tercero que de tal modo se le otorgan

\section{III.3.e.- El término}

El término es un momento futuro y cierto desde el que comenzaran a cumplirse los efectos de un contrato. Desde la antigüedad, encontramos referencias al tiempo de los contratos agrícolas. Ya autores como Virgilio, en sus Geórgias, emplea en contraposición al año natural, el agrícola, diciendo que si bien ambos se determinan por el movimiento de los astros, el primero pertenece a la cronometría mientras el segundo entra de lleno en el campo de la climatología y que mientras el año natural es invariable el agrícola se atempera a la producción de las cosechas y los frutos.

También en textos jurídicos medievales encontramos frecuentes referencias al día de San Miguel, 29 de septiembre, en el que se establecía la fecha límite para las faenas agrícolas de recolección y por ende también el de extinción de los contratos sobre la tierra. En este sentido, podemos citar el Fuero de Cuenca, Ley XXIII: "Esto es a saber: que ninguno a partir de la fiesta de San Miguel non ha de responder por daños de mies. Otrosí, ni el meseguero, ni el señor de la mies non han de responder por peños que tomasen, si fasta aquel día non fueren quitos”.

El término debe ser fijado por las partes, por un tercero, por la Ley e incluso cabe que su determinación sea señalado por un órgano judicial. El art. 1.128 del C.c. se refiere al término "tácito o implícito" al disponer que si la obligación no señalare plazo, pero sí de su naturaleza y circunstancias se dedujere que ha querido concederse al deudor, los tribunales fijarán la duración de aquél al igual que en el caso de que el plazo haya quedado a voluntad del deudor.

Como ejemplo de fijación del término del contrato por la Ley, lo encontramos en la Ley de Modernización de Explotaciones Agrarias que regula la duración del contrato de arrendamiento rustico, a partir de la entrada en vigor de este texto legal "de cinco 
años" ${ }^{24}$, y las prórrogas hablan a su vez de un término posible, pero siempre a voluntad de las partes, lo que supone una nueva etapa en el modo de regularse la relación entre arrendador y arrendatario. BALLARIN MARCIAL destaca que con esta Ley se acabaría con el colapso a que habían llegado los arrendamientos, para dar paso a un renacer de este contrato, donde el arrendatario será un profesional de la agricultura, a quien el propietario le confía la explotación de la finca, con la intención de obtener una mejor rentabilidad. En el artículo 28.3 del mismo cuerpo legal se señala que "El arrendatario podrá dar por extinguido el contrato al término de cada año agrícola...”.

En la casuística objeto de nuestro interés se establece como mínimo el de quince años pudiendo ser prorrogado por voluntad de las partes por periodos de cinco, en cinco años. Especial consideración merece el "dies ad quo", aquel en el que se inicie la intervención en la explotación a la que se hace referencia el convenio. En el supuesto de que existan varias fincas deberá entenderse que este es el primero de la realización de los trabajos en la primera de las fincas que conforman la explotación. De igual modo deberá procederse para determinar el "dies ad quem", o día de finalización del contrato a computar para todo la explotación.

Quizás podría parecer un plazo elevado, pero como posteriormente tendremos ocasión de analizar la gestión a realizar en el objeto del contrato justifica su dilación en el tiempo.

\section{III.3.f.- El precio}

No siempre el precio en los contratos agrarios viene representado por una cantidad de dinero, pues éste puede venir también representado o dado por: una parte alícuota de los frutos y estaremos ante la figura de la aparcería; o por una cantidad o calidad determinada de frutos y nos encontraremos con el contenido del art. 31.2. de la Ley de arrendamientos rústicos de $1980^{55}$; o por una mejora o transformación del fundo según se contiene en el artículo 2.3. de la misma Ley ${ }^{56}$.

En nuestro modelo de convenio, el precio lo es objeto de una consideración especial. En el primer párrafo de la cláusula dedicada a la renta, la misma se determina a través de la

\footnotetext{
54 28.1. de la Ley de Modernización de Explotaciones Agrarias, Ley 19/1995, de 4 de julio.

55 "Si, no obstante, la fijaren en especie, el contrato será válido, pero cualquiera de las partes podrá exigir la conversión de la renta en dinero, conforme a los criterios establecidos en el artículo treinta y ocho".

56 "Consistir el precio en una cantidad alzada para todo el tiempo del arrendamiento o, en todo o en parte, en la mejora o transformación del fundo arrendado".
} 
moneda de curso legal en nuestro país, cantidad que es simbólica, un euro, para el primer periodo de tiempo fijado para los quince años de vigencia del convenio.

Excepcionalmente, se prevé una suerte de situaciones, entre el cuarto y decimoquinto año de vigencia, en que alguna o algunas de las fincas que conforman el conjunto de la explotación se obtengan saldos contables positivos en alguna campaña, en dichos periodos. La Cooperativa, en estos periodos, liquidara al cedente el 50\% del saldo resultante, el día 30 de septiembre de cada periodo que se trate en la cuenta designada a tal efecto. A estos efectos, el mismo texto del acuerdo considera el saldo resultante como aquel "resultado obtenido después de descontar de la liquidación anual los gastos de la explotación e inversión habidos durante la campaña y una vez se haya recuperado el valor de la inversión inicial".

Desde estas líneas, entendemos, como luego diremos, que los pactos y estipulaciones que conforman la especificidad de este tipo contractual no puede ser asimilado al precio por tratarse de una obligación contractual consistente en actividad, servicio y prestación a realizar por la Cooperativa que en determinados supuestos y bajo ciertas condiciones es objeto de acuerdo, consecuentemente, queda desvinculado de la contraprestación por renta.

\section{III.3.g.- Las ayudas y pagos a la explotación}

A tenor del contenido de la autonomía de la voluntad de las partes, entre el contenido del convenio objeto de nuestra consideración se ha incluido la cesión a favor de la Cooperativa de cualquier tipo de ayuda que se pueda percibir en virtud de la explotación de la finca agraria y en particular del pago básico.

En cuanto a la cesión de derechos de pago básico, cualquier actuación o resolución jurídica en esta materia tendrá que ser llevada a cabo por la Administración competente en esta materia, aplicando la normativa comunitaria, nacional o autonómica correspondiente, así como las normas de procedimiento administrativo, sancionador, de control, y demás que procedan. 
Sólo será objeto de nuestro interés el análisis de los criterios para la gestión autorizadas de las comunicaciones de cesión de derechos de pago básico con respecto a los efectos de la Solicitud Unica (SU) del 2017.

En España se reconoce la posibilidad de que los derechos definitivos establecidos y comunicados a los distintos titulares durante el primer año de aplicación del régimen de pago básico en España puedan ser cedidos. Dicha cesión, según el art. 28 del Real Decreto $1076 / 2014^{57}$, implica el cambio de titularidad de los mismos con efectos en las siguientes campañas y como mucho hasta el $2020^{58}$. En dicha normativa, se establecen con criterios homogéneos para todo el territorio nacional. y para la aplicación de las retenciones correspondientes, esto es, para los peajes, cuyos importes son incorporados a la Reserva Nacional como se especifica en el art. $29^{59}$ de dicha norma. En su art. $30^{60}$ se relacionan con todo tipo de detalle, los requisitos que han de cumplir las instancias que deben presentarse por los interesados, a dicha solicitud deberán acompañarse los documentos que allí se especifica, a los que luego nos referiremos.

Para que los derechos de pago básico (dpb) puedan ser cedidos es necesario que dichos derechos se hayan asignado definitivamente a un titular. Consecuentemente, sólo cuando exista una asignación definitiva de derechos de pago básico , su titular podrá cederlos con efectos para las siguientes campañas. Dicha transmisión puede ser en virtud de venta, arrendamiento o mediante cualquier otra forma admitida en derecho, con el límite territorial de la propia región en la que fueron asignados ${ }^{61}$. Recordemos que la base territorial de las regiones quedó fijada de forma definitiva en una capa de referencia sobre el SIGPAC, una vez finalizado el proceso de asignación de derechos de pago básico en el año 2015.

\footnotetext{
${ }^{57}$ Modificado por el Real Decreto 1172/2015, de 29 de diciembre y por el Real Decreto 745/2016 de 30 de diciembre

58 art. 1.2. RD1076/2014, establece su aplicación para la asignación de los derechos de pago básico para el periodo de 2015-2020.

${ }^{59}$ Modificado por el Real Decreto 1172/2015, de 29 de diciembre y por el Real Decreto 745/2016 de 30 de diciembre

${ }^{60}$ Modificado por el Real Decreto 1172/2015, de 29 de diciembre

${ }^{61}$ art. 28.1 Real Decreto 1076/2014
} 
Los derechos de pago(dpb) sólo podrán transferirse a un agricultor considerado activo ${ }^{62}$, salvo en las herencias, que no será exigible al heredero en caso de que este ceda definitivamente los derechos a un tercero que si lo sea.

Los distintos tipos de cesiones admitidas se describen en al art. $29^{63}$ y también se contemplan las retenciones o peajes a aplicar, en su caso. Dicha solicitud la realiza el cedente aunque en la práctica es el concesionario el que la presenta junto toda la documentación necesaria debidamente suscrita por el cedente. En el modelo objeto de nuestro estudio existe una clausula de cesión expresa de estos derechos de pago básico, bien entendido que afecta a aquellos, como hemos referido en líneas anteriores, reconocidos de forma definitiva y será esta la que se ocupe de dicha gestión, dado que es a la Cooperativa a quien más le conviene asegurarse que la cesión se tramita con éxito, caso contrario, no dispondrá de los derechos y no cobrará las ayudas.

La Cesión que deberá ser comunicada, en el presente supuesto, a la Conselleria d'Agricultura, Medi Ambient, Canvi Climàtic i Desenvolupament Rural, la competente para estudiar las cesiones; a través de la Dirección General de Desarrollo Rural y PAC .

La solicitud de comunicación de la cesión de derechos que presentara la Cooperativa deberá contener, como mínimo, la siguiente información

1.- Identificación del titular cedente de los derecho dependiendo de si es persona física o jurídica el documento lo acredite será distinto.

2.- Identificación de la Cooperativa a cuyo favor se hace la cesión.

3.- Fecha de la cesión

4.- Tipo de cesión solicitada, debiendo especificar el tipo de cesión de que se trata.

5.- Número de años para el que se constituye el mismo.

6.- Fecha de la comunicación.

7.- Códigos de los derechos transferidos

\footnotetext{
62 art. 28.4. Real Decreto 1076/2014

63 art. 29 del. Real Decreto 1076/2014, modificado por el Real Decreto 1172/2015, de 29 de diciembre y por el Real Decreto 745/2016 de 30 de diciembre
} 
8.- Porcentaje transferido de los derechos implicados en la cesión

\section{9.- Firma de los intervinientes}

10.- Lista de documentos aportados como adjuntos a esta solicitud

El plazo general es el que prevé el RD 1076/2014, no obstante, en cada Comunidad Autónoma se puede establecer de forma específica, de tal modo que el día "ad quo" o de inicio se posponga del establecido en el art. $30.1^{64}$, el día 1 de noviembre, y se mantiene el día "ad quem" o final, con el de finalización del plazo de presentación de la solicitud única del siguiente año. En la Comunidad Valenciana ${ }^{65}$, como dicha normativa permite que cada comunidad autónoma ajuste este periodo de solicitud, por lo general, se hace coincidir el periodo de presentación de las cesiones con el de la SU de cada año, no obstante, para el año 2018, de manera excepcional, la fecha de inicio se ha establecido en el 27 de febrero de 2018, haciéndola coincidir con el inicio del plazo de la solicitud única, ello por en atención a la necesidad de disponer de las bases de datos de SIGPAC y de derechos de pago básico actualizadas.

Si la administración en el plazo de seis meses, desde la comunicación de la cesión, no ha notificado motivadamente su oposición se entenderá que dicha cesión ha sido aceptada .

La transmisión de estos derechos al incluirse como elemento de la explotación constituyendo una unidad, esto es, se transmite íntegramente la explotación, no está sujeta a IVA.

\section{III.3.h.- La formula de resolver las controversias: mediación}

Las formulas de resolución alternativa de conflictos han sido objeto de la consideración de las instituciones nacionales y supranacionales. Detengámonos en la figura de la mediación, regulada, en el ámbito de la UE través de la Directiva 2008/52 del Parlamento y del Consejo de la Unión Europea ${ }^{66}$, y , en nuestro país, en la Ley 5/2012 ${ }^{67}$.

\footnotetext{
${ }^{64}$ Real Decreto 1076/2014, modificado por el Real Decreto 1172/2015, de 29 de diciembre.

65 Resolución de 2 de octubre de 2017, de la Direcció General de Desenvolupament Rural i Política Agrària Comuna, de modificació de l'inici del termini per a comunicar les cessions de drets de pagament bàsic a la Comunitat Valenciana, corresponent a l'any 2018, publicada en el DOGV núm. 8148, de $13 / 10 / 2017$.

66 DIRECTIVA 2008/52/CE DEL PARLAMENTO EUROPEO Y DEL CONSEJO de 21 de mayo de 2008 sobre ciertos aspectos de la mediación en asuntos civiles y mercantiles. Diario Oficial de la Unión Europea L 136/3, de 24 AGOSTO 2008. http://eur-lex.europa.eu/oj/direct-access.html.
} 
La mediación debe ser entendida como un procedimiento estructurado, sea cual sea su nombre o denominación, en el que dos o más partes en un litigio intentan voluntariamente alcanzar por sí mismas un acuerdo sobre la resolución de su litigio con la ayuda de un mediador ${ }^{68}$.

La mediación, en la normativa nacional, se excluye, expresamente su aplicación en materia penal, en la administración pública, en lo laboral y en materia de consumo, consecuentemente, puede ser aplicada en el ámbito agrario ${ }^{69}$. Instrumento que se ha implementado en las relaciones comerciales entre las organizaciones de productores y los compradores, con el fin de mejorar el funcionamiento de la cadena alimentaria ${ }^{70} \mathrm{y}$ fomentar un mayor equilibrio, dejando en manos de las partes, como no podía ser de otro modo, la posibilidad de su uso, en tal sentido el Decreto 64/2015 $5^{71}$. Los compromisos acordados por las partes y suscritos en el acuerdo de mediación son directamente ejecutables ${ }^{72}$ como si de una Sentencia Judicial se tratará, sólo será necesario solicitar en cumplimiento de su contenido a tenor del art. 517.2.2.de la L.E.Cv, al igual que debe instarse con cualquier Resolución Judicial .

Las relaciones que surgen al amparo de este convenio, al igual que ocurre en otros campos de las relaciones humanas, pueden conllevar conflictos, dada la cercanía y múltiples nexos interpersonales existentes entre los vecinos de comunidades territoriales como son los municipios de Benaguasil, Vilamarxant y los términos municipales de los

67 La finalización del plazo de incorporación al ordenamiento jurídico español de la Directiva 2008/52/CE, el 21 de mayo de 2011, obligo a regular la materia a través del Real decreto-ley 5 /2012, para adaptar de nuestro Derecho y evitar ser sancionados por las instituciones de la Unión Europea, hoy derogado por la vigente regulación Ley 5/2012 de Mediación Civil y Mercantil.

${ }^{68}$ Concepto que podemos encontrar en el art. 3a de la Directiva y en el art. 1 de la Ley 5/2012.

${ }^{69}$ DOMENECH MARTINEZ, G. "La mediación, una herramienta en la solución de controversias en materia alimentaria". Temas actuales de Derecho agrario y alimentario. Editorial Universitat Politècnica de València.València.2016. pág.91.

${ }^{70}$ MADRAZO MELÉNDEZ.B."El acuerdo de mediación extrajudicial de pagos para el empresario individual agrario". Tratado de Derecho Agrario..(Muñiz Espada E y Amat Llombart,P Direct).Wolters Kluwer 2017.pág. 568. DOMENECH MARTINEZ, G. "Algunas características de la Ley 2/2000 reguladora de los contratos tipoagroalimentarios en España". Desafios Do Direito Agrário Contemporâneo. Altai Ediçòes. RibieraoPreto.2014. pág.216 y DOMENECH MARTINEZ, G "Las organizaciones interprofesionaels en las disposiciones en las disposiciones normativas españolas y la contratacion de productos agroalimentarios". Tratado de Derecho Agrario..(Muñiz Espada E y Amat Llombart,P Direct).Wolters Kluwer 2017. pags. 435 y 440y 441 DOMENECH MARTINEZ, G "La comercialización de los productos agroalimentarios a través de los contratos tipo de productos agroalimentarios y la mediación en la resolución de sus controversias, Aspectos legales de la agricultura sostenible. Slovak University of Agricultura in Nitra. Nitra. 2013.pág. 378 a 380

${ }^{71}$ De 6 de febrero de 2015 por el que se desarrolla parcialmente la Ley 12/2013, de 2 de agosto, de medidas para mejorar el funcionamiento de la cadena agroalimentaria, y se modifica el Reglamento de la Ley 38/1994, de 30 de diciembre, reguladora de las organizaciones interprofesiones agroalimentarias, aprobado por Real Decreto 705/1997, de 16 de mayo. BOE de 7 febrero 2015, pag. 10337 y sig.

${ }^{72}$ DOMENECH MARTINEZ, G., obra citada. pág. 101 
pueblos de su entorno la elección de una fórmula alternativa de resolución de conflictos es una buena opción con el fin de perseverar las relaciones fluidas entre la comunidad en la que la Cooperativa desarrolla su actividad y entre ellas la elección de la mediación, consideramos que es la más adecuada, porque extrae la solución del conflicto de la voluntad de un tercero, para empoderar a las partes en la búsqueda de la solución que satisfaga a ambas y restablecer la paz social en la comunidad en la que interrelacionan, en sentido estricto, las propias partes del conflicto y, en sentido amplio, las redes de influencia su entorno.

Consecuentemente, de todo lo anteriormente expuesto, del clausurado del contrato se desprende que el contrato de gestión y planificación de la producción auspiciado por la Cooperativa es un instrumento que promueve la producción planificada, la gestión de las parcelas abandonadas y refuerza la gestión de dirección y el liderazgo de la Cooperativa, añadiendo a su papel de mera comercializadora un plus en pro de uno más proactivo. De tal modo que deviene el centro de decisión en torno a la toma de decisiones sobre la gestión y planificación de las parcelas, asumiendo aquellas decisiones referidas a la variedad a cultivar, el momento de su recolección y los tratamientos durante el cultivo.

\section{IV.- CONCLUSIONES}

1.-El sector agroindustrial es importante en nuestro país

2.- En la Comunidad Valencia existen dificultades estructurales que necesitan de proyectos de ordenación del territorio que proyecten un futuro agrario sostenible, con iniciativas que protejan el suelo agrario al tiempo que plantean estrategias de desarrollo agrario en el territorio de la comunidad autónoma y la agroindustria ofrece una excelente oportunidad para el desarrollo del mismo

3.- Desde las instituciones se llevan adelante iniciativas para fomentar la actividad agraria en el campo valenciano a través de instrumentos de carácter medioambiental como son los Bancos de tierra y los Huertos Urbanos Municipales 
4.- Desde el ámbito privado, la Rural San Vivent Ferrer Coopv se insta como alternativa a la elevada tasa de abandono de cultivos a la vez que implementara su actividad como entidad productora que permitirá potenciara su papel de comercializadora de los productos agrarios. un programa de gestión en común y planificación de la producción. Iniciativa auspiciada desde la Fundación Caja mar y el Departamento de Economía y Ciencias Sociales (DECS) de la UPV

5.- El proyecto pretende incorporar tierras en producción y mejorar su rentabilidad bajo la dirección de la Cooperativa a través de dos vías: reconversión directa por los agricultores y reconversión por cesión de las explotaciones. Es a través de esta última donde surgen los contratos de gestión y planificación de la producción.

6.- Al contrato de gestión y planificación de la producción suscrito por la Rural San Vicente Ferrer de Benaguacil Coopv debe aplicarse la doctrina general del contrato y las disposiciones que con carácter general se establecen en nuestra legislación.

7.- -- Se trata de un contrato agrícola, en el que una de las partes es la Rural San Vicente Ferrer de Benaguacil Coopv en cuyo contenido además de los elementos esenciales para su validez, encontramos, bajo el auspicio de la libertad de la voluntad de los contratantes, otras cláusulas pretende mejorar la rentabilidad de las explotaciones a través de una mayor dirección y liderazgo por parte de la Cooperativa de las decisiones que rigen la campaña de producción

8.- Se trata de un contrato para la explotación agraria y como parte del contenido especifico de este contrato podemos destacar: el objeto, el precio, su duración y la cesión de los derechos de pago básico, 


\section{BIBLIOGRAFIA}

AMAT LLOMBART.P. "La explotación agraria, sus elementos integrantes y tipos cualificados de explotación. La reforma legislativa pendiente" Tratado de Derecho Agrario..(Muñiz Espada E y Amat Llombart,P Direct).Wolters Kluwer. 2017

ATANCE MUÑIZ,I. Sostenibilidad económica de la agricultura española La Sostenibilidad de la Agricultura Española. CAJAMAR CAJA RURAL. (REIG MARTINEZ,E y GOMEZLIMON J.A Coord). ALMERIA.2013

BOLLA "Contrato Agrario" en Nuovo Digesto I, Torino 1938

CARROZZA.A. "Estratto dall'apendice del novisimo digestio italiano". Ediciones Utet. Turin.198, pag.7 y

CASTÁN TOBEÑA,J. Derecho Civil Español y foral. Tomo III

COMPÉS LÓPEZ, R, MARTINEZ ARROLLO, F, CAMARENO, L, Territorios rurales, la evolución de las políticas de desarrollo rural y la aplicación del segundo pilar de la pac 20142020 en España. Redes de innovación y desarrollo local en el medio rural (COMPÉS LÓPEZ R, ALVAREZ GARCIA-COQUE,J.M, y AGUILAR-AVILA Coord), MAAMA. MADRDI. 2015

DE LA CUESTA, J.M ${ }^{a}$ Comunicación al II Congreso Europeo y I Iberoamenricano de Dereccho Agrario, Almería 1997.

DE LOS MOZOS J.L.

*Estudios de Derecho Agrario. Editorial Tecnos., Madrid, 1972

*“El Objeto del Negocio Jurídico”, en Revista de Derecho Privado, 1960.

DIEZ-PICAZO, L. En Fundamentos del Derecho Civil Patrimonial, Vol. I Introducción, Teoría del Contrato, Las relaciones Obligatorias, Editorial Tecnos, $3^{\text {a }}$ edición 1979

DOMENECH MARTINEZ, G.

*Los contratos de integración agroindustrial. Ediciones Cooperativas. Buenos Aires.2010.

*"La comercialización de los productos agroalimentarios a través de los contratos tipo de productos agroalimentarios y la mediación en la resolución de sus controversias. Aspectos legales de la agricultura sostenible. Slovak University of Agricultura in Nitra. Nitra. 2013

*"Algunas características de la Ley 2/2000 reguladora de los contratos tipoagroalimentarios en España". Desafios Do Direito Agrário Contemporâneo. Altai Ediçòes. RibieraoPreto.2014

*"La mediación, una herramienta en la solución de controversias en materia alimentaria". Temas actuales de Derecho agrario y alimentario. Editorial Universitat Politècnica de València.València.2016 
*"Los Bancos de Tierra en la Comunidad Valenciana". Fuentes, Política Agraria y Desarrollo Rural, Justicia Agraria y Paz Social. Editorial Jurídica Continental. Costa Rica.2016.

*"Las organizaciones interprofesionales en las disposiciones en las disposiciones normativas españolas y la contratacion de productos agroalimentarios". Tratado de Derecho Agrario.(Muñiz Espada E y Amat Llombart,P Direct).Wolters Kluwer 2017.

GALGANO F. El Negocio Jurídico, Traducción realizada por Blasco Gascó y Prats Albentosa, Tirant lo Blanc, Valencia, 1992

GOMEZ LOPEZ, J. D. " Las cooperatvas agrarias de la Comunidad Valenciana" Cuadernos de Geografia. núm. 75, 2004

GOLDONI, M." La nozione di contratto agrario. ETS. Ed. Pisa.1988.

GUERRA DANERI, E. "Bases de la Calificación del contrato Agrario". Revista Argentina de Derecho Agrario, año, 3, núm. 4 septiembre de 1994..

LÁNDERER N. Acciones de aumento del valor añadido de la producción. Estrategias Colectivas para el Desarrollo Rural: El Caso de las Cooperativas de la Comunidad Valenciana. (ORTIZ,D y MESTRE, M Coord.). FECOVA.VALENCIA. 2008

LUNA SERRANO, A. Rivista de Dirrito Agrario, 1975, núm. 4.

MADRAZO MELÉNDEZ.B."El acuerdo de mediación extrajudicial de pagos para el empresario individual agrario". Tratado de Derecho Agrario..(Muñiz Espada E y Amat Llombart,P Direct).Wolters Kluwer 2017.

MARTIN BALLESTERO Y COSTEA Teoría general del contrato agrario en Rivista de Dirito Agrario Casa Editrice Dott. A. Giuffrè - Milano, 1971,

MELICH ORISNI, J. Doctrina General del Contrato, $3^{\text {a }}$ Edc. Marcial Pons, Caracas, 1997.

PASTORINO, L.F. Derecho Agrario Argentino, Abeledo Perrot, Buenos Aires, 2009.

REIG MARTINEZ, E y GOMEZ- LIMON, J.A. La sostenibilidad de la agricultura actual. La Sostenibilidad de la Agricultura Española. CAJAMAR CAJA RURAL. (REIG MARTINEZ,E y GOMEZ- LIMON J.A Coord). ALMERIA.2013.

SANCHEZ HERNANDEZ, A.

* "El contrato Agrario" El Derecho Agrario: Modernización y Desarrollo Rural . Tiran lo Blanc.,2001 .

*"Clasificación Básica de los Contratos Agrarios". Manual de Instituciones de Derecho Agroambiental Euro-Latinoamenricano 


\section{Revista Internacional de}

Doctrina y Jurisprudencia volumen 17, Diciembre de 2017 TUDELA MARCO, L Y GARCIA ALVAREZ-COQUE,J.M (Coordinadores). Innovación en la gestión y modernización de la producción en una cooperativa citrícola. Cajamar Caja Rural.España.2016. 